MATEC Web of Conferences 17, 01012 (2014)

DOI: $10.1051 /$ matecconf/ 20141701012

(C) Owned by the authors, published by EDP Sciences, 2014

\title{
Improving Stack Effect in Hot Humid Building Interiors with Hybrid Turbine Ventilator(s)
}

\author{
Radia Tashkina Rifa ${ }^{1}$, Karam M. Al-Obaidi ${ }^{2}$, Abdul Malek Abdul Rahman, \\ ${ }^{1,2,3}$ School of Housing, Building and Planning, Universiti Sains Malaysia, 11800, Penang, Malaysia
}

\begin{abstract}
Natural ventilation strategies have been applied through the ages to offer thermal comfort. At present, these techniques could be employed as one of the methods to overcome the electric consumption that comes from the burning of disproportionate fossil fuel to operate air conditioners. This air conditioning process is the main contributor of $\mathrm{CO}_{2}$ emissions. This paper focuses on the efficiency of stack ventilation which is one of the natural ventilation strategies, and at the same time attempts to overcome the problem of erratic wind flow and the low indoor/outdoor temperature difference in the hot, humid Malaysian climate. Wind flow and sufficient pressure difference are essential for stack ventilation, and as such the irregularity can be overcome with the use of the Hybrid Turbine Ventilator (HTV) which extracts hot air from the interior of the building via the roof level. The extraction of hot air is constant and consistent throughout the day time as long as there is sunlight falling on the solar panel for solar electricity. The aim of this paper is to explore the different HTV strategies and find out which building dimensions is most expected to reduce maximum indoor air temperature of a given room in a real weather condition.
\end{abstract}

\section{Introduction}

The building industry is one of the major energy consumers around the globe. The present situation of energy consumption has become a concern as the demand is increasing tremendously but production is not in tandem. Many countries in the tropical zone are exposed to high temperatures and humidity levels and the population of these countries are frequently the users of purchased energy i.e. airconditioners in a greater amounts. In such a climate the average air temperature remains high. Air conditioners are the most widespread means of achieving thermal comfort. This is one of the ways which caused the demand for fossil fuel energy made from coal, oil, gas or from uranium. If this trend carries on, then the limited natural resources will become very expensive to feel thermally comfortable [1]. To overcoming problems of overheating and the rapidly growing energy consumptions, building designers are applying strategies to use natural ventilation techniques. An investigation done on an empirical and low speed tunnel with roof turbine ventilators on 14 bathrooms in a dormitory block in Taiwan showed that the combination of roof ventilators and bathroom exhausts achieved ample air change rate in the bathrooms [2]. Moreover, the configuration of the turbine ventilator affected the performance of the ventilation rate and to further explore this, a research was conducted to find out the effects of the blade design on the ventilation and the result showed that the curved vane ventilator had a $25 \%$ larger airflow than the straight one [3].

${ }^{\text {a }}$ Corresponding author : malik@,usm.my 
Another experiment conducted to investigate the performance of a HTV under low outdoor wind conditions showed that the internal extractor fan increased the ventilation rate at an outdoor wind speed of 0 and $5 \mathrm{~m} / \mathrm{s}$, but at the same time the ventilation rate was not enhanced in the presence of outdoor wind speed, and a rotational speed of $1500 \mathrm{rpm}$ was required for the fan to be used [4].

A full- scale empirical study was carried out to find out the most effective application of the HTV in order to improve the indoor thermal conditions in the hot and humid climate of Malaysia. With three different strategies (Fig. 1) the indoor air temperature, relative humidity and air velocity were investigated. It was found that the strategy which had the extractor fan at the occupied level was the most efficient one as it could reduce the indoor temperature by $0.70{ }^{\circ} \mathrm{C}$ and the relative humidity by $1.7 \% \mathrm{RH}$. Besides that, it could induce an air velocity of $0.38 \%$ in the occupied level [5].

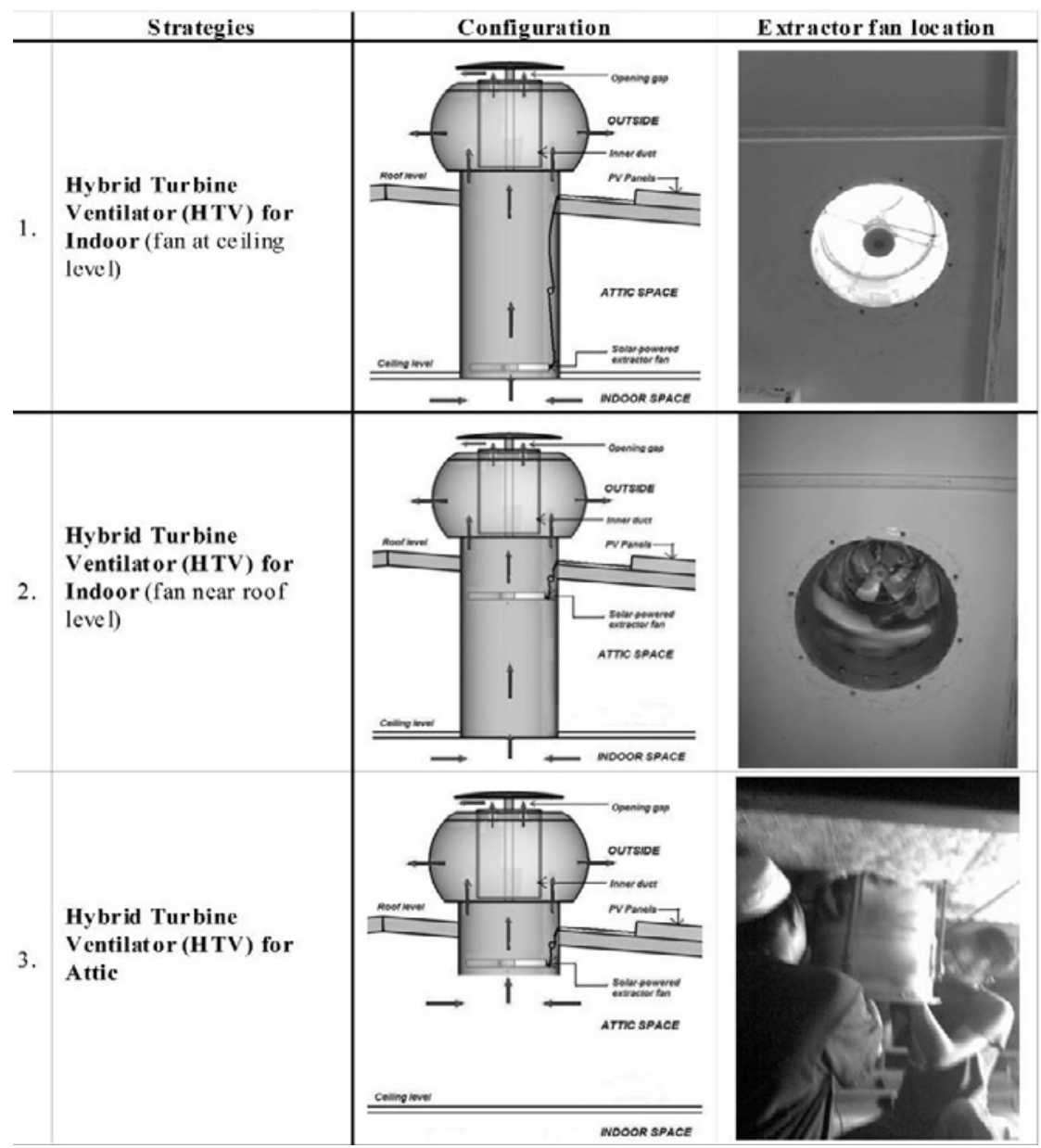

Fig .1: Three different types of HTV application [5]

Another full scale study was conducted in real climatic conditions to explore attic ventilation with a single HTV for a specific volume of air in vented and unvented conditions. The experiment showed that the temperature of a vented attic could be brought down by $6.40{ }^{\circ} \mathrm{C}$ and the relative humidity found was between $40-50 \%$ which was $10 \%$ more than the unvented condition, but still at an acceptable level for energy conservation and extension of the attic material lifespan. Moreover, the inclusion of a $50 \mathrm{~W}$ solar panel with a turbine ventilator gave an outcome of attic air velocity which exceeded $1.3 \mathrm{~m} / \mathrm{s}$ at a solar radiation value of $800 \mathrm{~W} / \mathrm{m} 2[6]$. 
To further explore the effectiveness of the HTV, an experiment was conducted and it was found that a given specified hybrid turbine ventilator which extracts hot air from a room within specific volume of air mass could reduce the indoor temperature of the said room.

\section{Experimental Setup}

The real scale experiment was done under real climatic conditions in Universiti Sains Malaysia (USM) at School of Housing, Building and Planning (Location: latitude 50, 21' N, and longitude $1000,18^{\prime}$ E) (Fig. 2). It was carried out in four stages and the data were collected during the hot and sunny days of March to May in the year 2014. The first stage was carried out in a closed unvented condition, whereas the next stages involved a combination of stack, cross and one sided ventilation (Table 1).
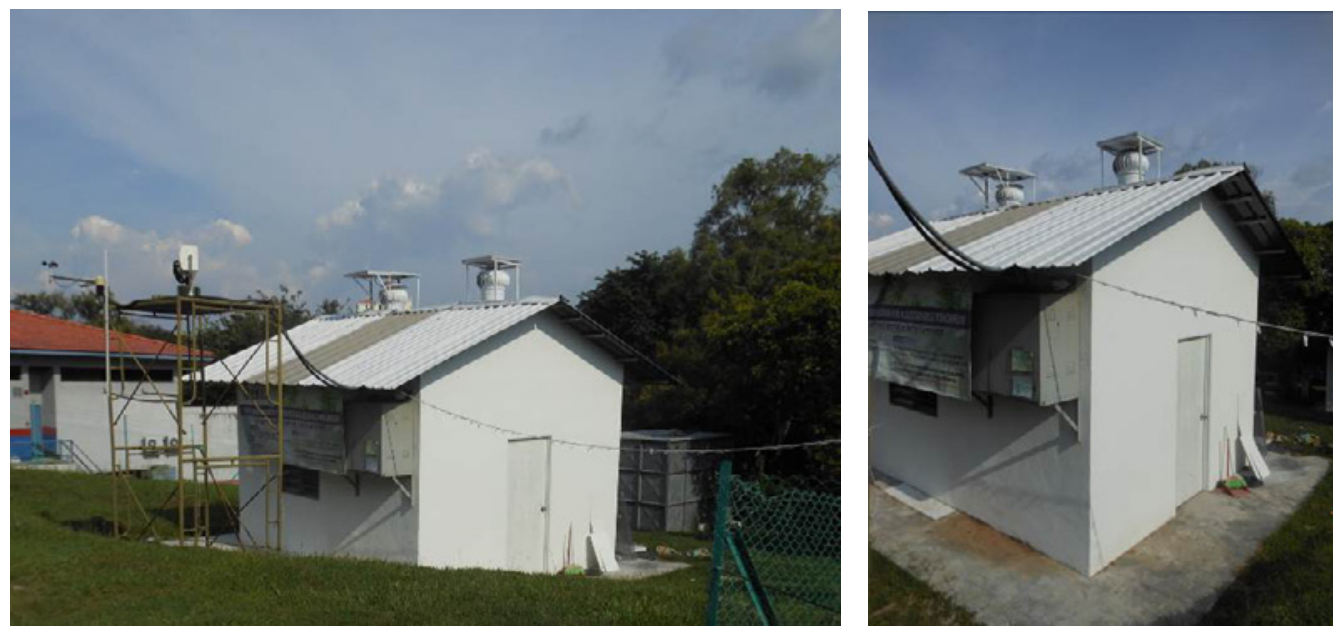

Fig. 2: The real scale model for the empirical study.

\subsection{Model Description}

The research model is a real full scale model; the walls are made of bricks of $10 \mathrm{~mm}$ thick and finished with a $2 \mathrm{~mm}$ plaster; the 300 pitched roof is made of aluminium sheets that are $1 \mathrm{~mm}$ thick. (Fig. 3)

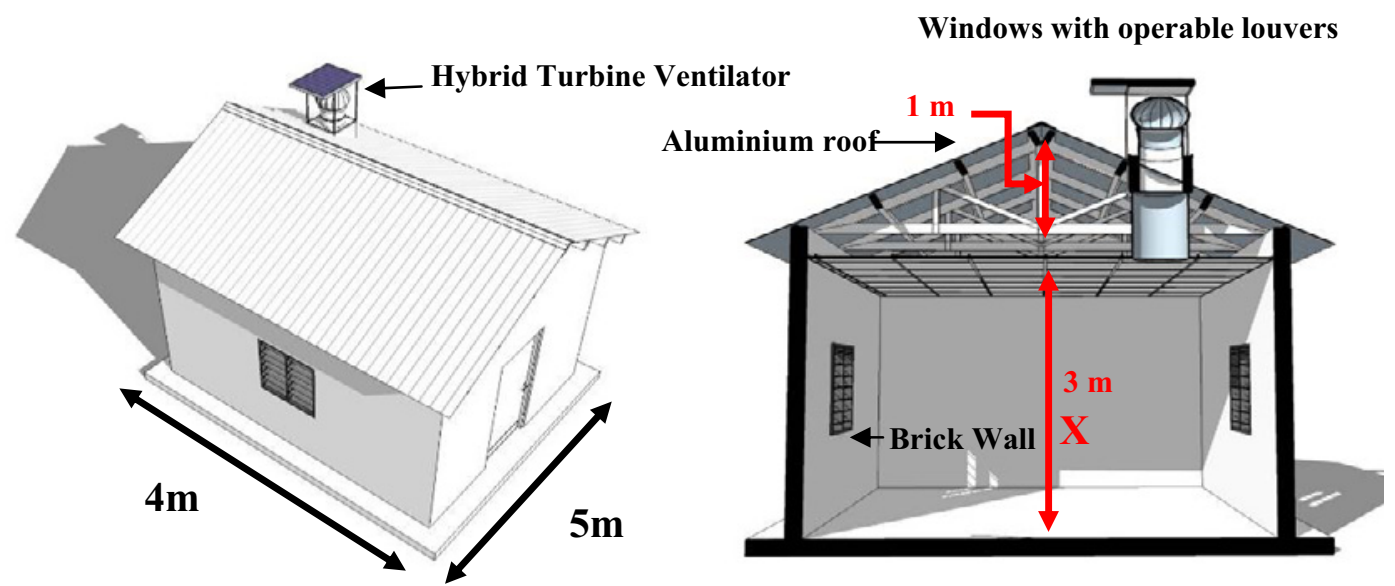

Fig. 3: ' $\mathrm{X}$ ' is the spot where the measurements were taken 
The room is $4 \mathrm{~m}$ wide, $5 \mathrm{~m}$ long and $3 \mathrm{~m}$ in height from floor to ceiling, whereas from the ceiling to the roof ridge is $1 \mathrm{~m}$ in height. Each window dimensions are $1 \mathrm{~m} \times 1 \mathrm{~m}$ with operable louvers. The turbine ventilator $(480 \mathrm{~mm}$ diameter), the extractor four-bladed fan $(300 \mathrm{~mm}$ diameter) and a $50 \mathrm{~W}$ polycrystalline solar panel are from separate suppliers concocted as one functional device operated by solar electricity.

\subsection{Stages of Experiment}

Four stages were taken into account. The first stage was conducted in an unvented condition so that it could later be used as a baseline reference.

Table 1: Stages of Experiment

\section{Stages}

\section{Conceptual Diagram}

\section{Closed Condition}

\section{Stage 01}

This strategy was for obtaining the data which would be used as the base case for comparisons. This phase is considered as the worst-case condition.

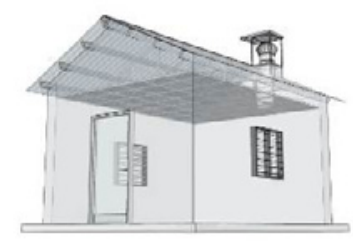

\section{Stage 02}

\section{Stack ventilation (Occupant's zone)}

This strategy was based on induced ventilation in the occupant's zone with the HTV switched on. The data was recorded and compared to see if the HTV in such a situation could lower the room

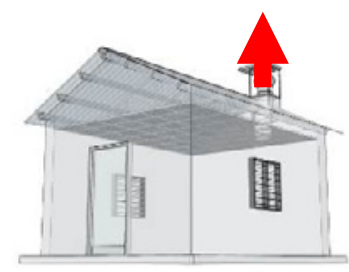
temperature.

\section{Stage 03 \\ One- sided Ventilation + Stack ventilation \\ (Occupant's zone)}

This strategy added natural one-sided ventilation to the second method in order to observe any further reduction in temperature.

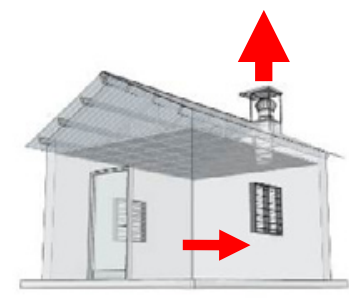

\section{Stage 04}

\section{Cross Ventilation + Stack ventilation}

(Occupant's zone)

This strategy added natural cross ventilation to the previous strategy in order to observe any further reduction in temperature.

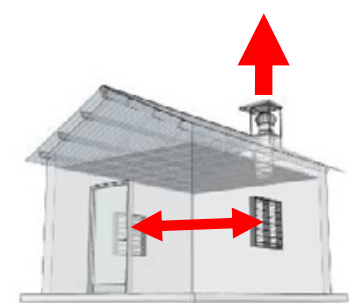

The data collected by the environment data logger are represented in terms of graphical representation for clearer analysis. The aim is to determine under which of the four stages the effective temperature difference occurs. The temperature difference is used as the reference, rather 
than the actual temperature reduction, because the stages of measurement were taken at different times of the year at one test bed i.e. the actual model house. Ideally there should be four model houses with measurements via a data logger that ran concurrently, but this was not possible and therefore the temperature difference is used as a scientific comparison.

The data collection was done with several instruments (Table 2) that were placed at the occupant's level indoor, and some of the sensors were placed at the outdoor station (see Fig. 3). The data were recorded in an environmental data logger (BABUC) and then transferred to a computer for further processing.

Table 2: The different types of sensors used in the experiment

\begin{tabular}{|c|c|c|}
\hline Sensor & Model & Properties \\
\hline Indoor air temperature & TE duct and immersion & $\begin{array}{c}\text { Used to observe air or water temperature. Can } \\
\text { measure temperature within a range of }-400 \\
{ }^{\circ} \mathrm{C}-1500{ }^{\circ} \mathrm{C} .\end{array}$ \\
\hline Outdoor air temperature & NRG \# 110S & $\begin{array}{c}\text { Used to measure air temperature and consists } \\
\text { of six plate radiation shields. Can measure } \\
\text { temperature within a range of }-400{ }^{\circ} \mathrm{C}-52.50 \\
\mathrm{C} .\end{array}$ \\
\hline Indoor relative humidity & HMP75 & $\begin{array}{c}\text { Used to measure relative humidity with high } \\
\text { accuracy level; measurement of accuracy of } \\
\pm 1.0 \% \mathrm{RH}(0-90 \% \text { RH). }\end{array}$ \\
\hline Indoor air velocity & Extech SDL 350 & $\begin{array}{c}\text { The hot wire anemometer measures the air } \\
\text { velocity. Air Velocity/Air Flow meter with } \\
\text { telescoping probe designed to fit into HVAC } \\
\text { ducts and other small openings. }\end{array}$ \\
\hline
\end{tabular}

\section{Results and Discussion}

\subsection{Air Temperature}

The graphs in Figures 4 (a) (b) (c) and (d) show the indoor and outdoor air temperature on the selected three hottest days in the months of March, April and May 2014. The findings are as follows:

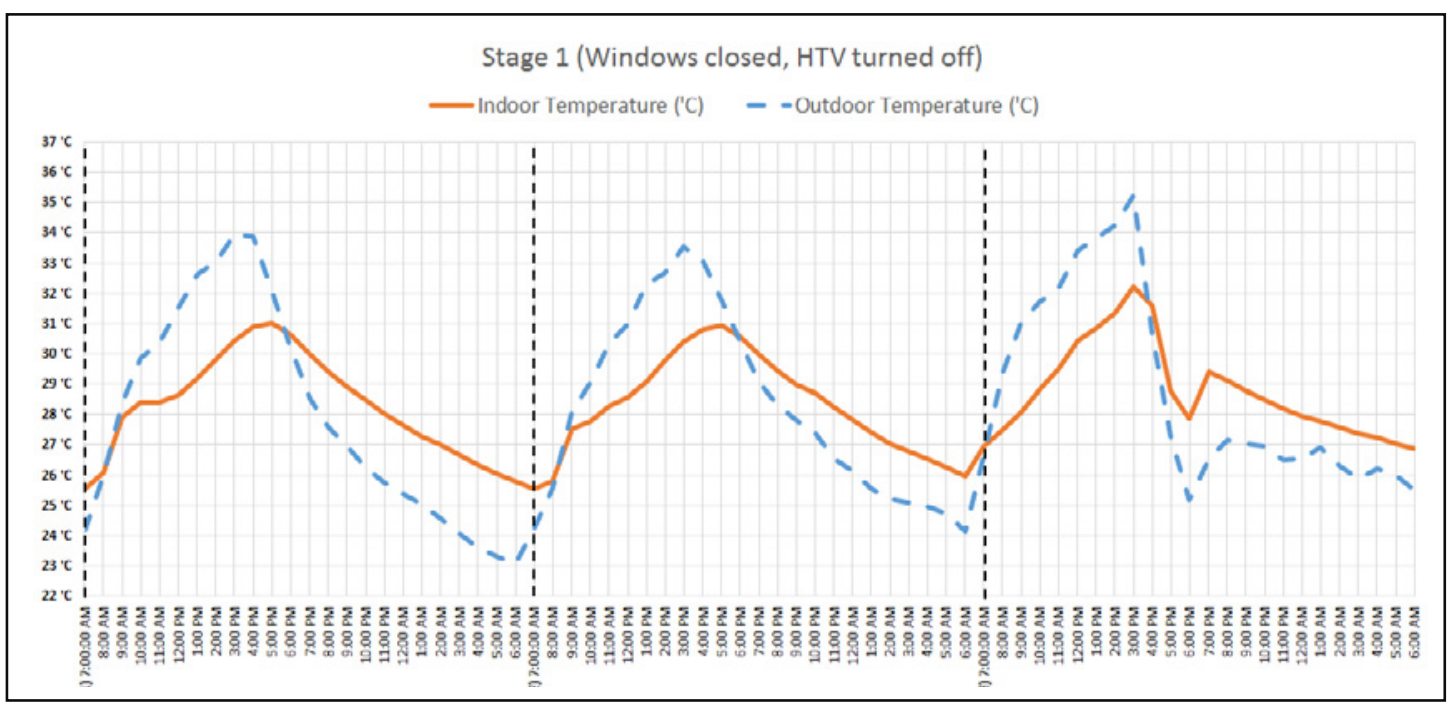

Figure 4 (a): Indoor air temperature at Stage 1 
a. Stage 1: Since it was a closed condition there is no reading for air movement indoors. The outdoor pattern is the normal behavioural pattern for a typical hot day in Malaysia. Typically for these selected 3 days there was a temperature equilibrium for about 1 hour between 8.00$9.00 \mathrm{am}\left(1^{\text {st }}\right.$ day) $9.00-10.00 \mathrm{am}\left(2^{\text {nd }}\right.$ day) $7.00-8.00 \mathrm{am}\left(3^{\text {rd }}\right.$ day $)$ before the outdoor temperature become much hotter than the indoor air temperature. The outdoor temperature peaked at $4.00 \mathrm{pm}\left(1^{\text {st }}\right.$ day $), 3.00 \mathrm{pm}\left(2^{\text {nd }}\right.$ day) and $3.00 \mathrm{pm}\left(3^{\text {rd }}\right.$ day $)$ before it descended to cross paths with the indoor temperature at between $4.00-6.00 \mathrm{pm}$. This is a total of $8-9$ hours that the indoor air temperature is lower than outdoor. The indoor air temperature became warmer than the outdoor surprisingly at $6.00 \mathrm{pm}$ for all the 3 days and stretched up to 8.00 $9.00 \mathrm{am}$ the next day. This is understandably correct because the stored heat from the building fabric began to its release. During the daytime, the building fabric stored the heat when exposed to the sun for about 8 to 9 hours. When the sun began to subside, the outdoor air gradually cooled and according to the law of heat transfer, re-radiation indoors took over. Since there was no ventilation, the indoor air temperature lasted about 14 to 15 hours. The temperature difference was found to be around $3.03{ }^{\circ} \mathrm{C}$.

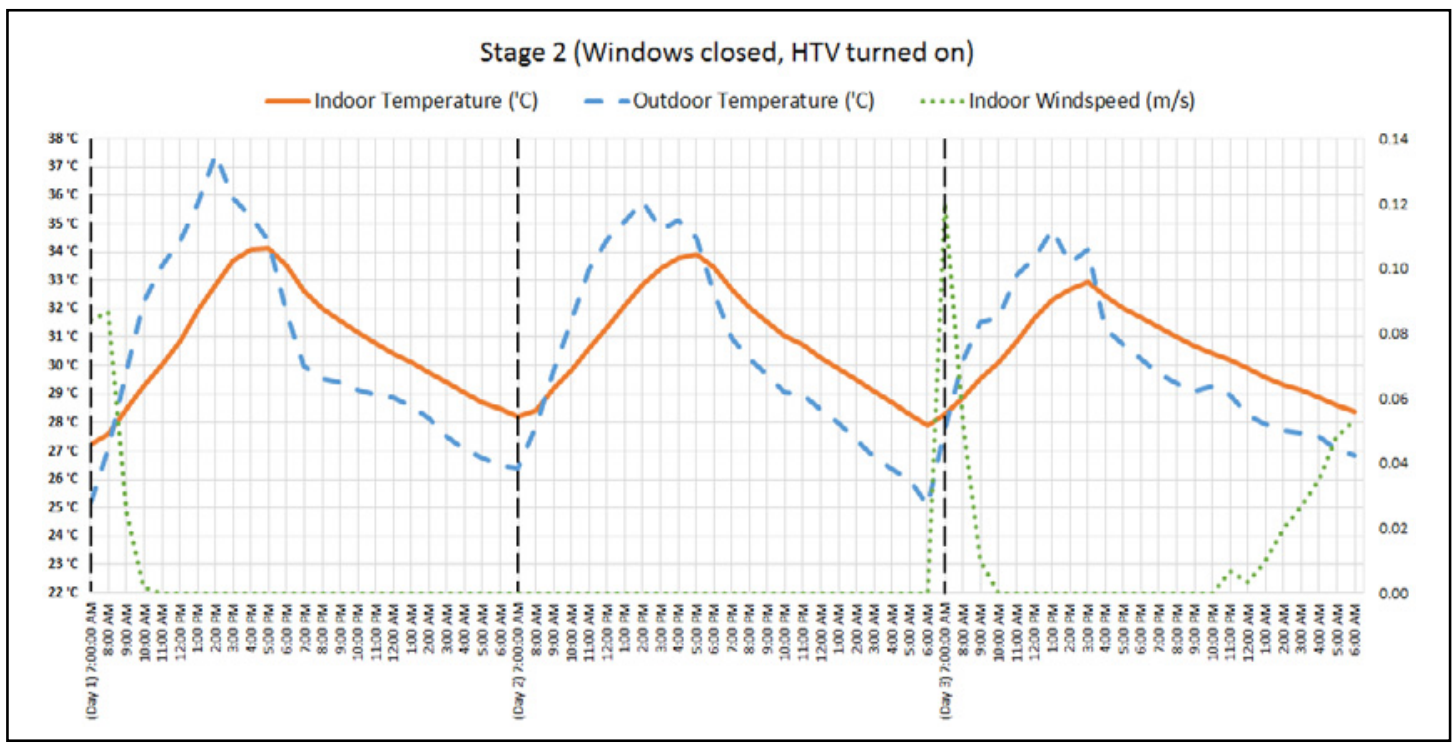

Figure 4 (b): Indoor air temperature at Stage 2

b. Stage 2: This stage was also a closed condition except that the HTV was switched on. The thermal behavioural pattern was almost similar to Stage 1 but there seemed to be some air movement. Unfortunately, although the graph shows some extreme pattern peaking at about $7.00 \mathrm{am}$, the air velocity was still considered too low to make any significant impact to cause an effective temperature reduction. Most of the time it was below $0.1 \mathrm{~m} / \mathrm{s}$. And so if there was no inlet of fresh air, the situation would remain almost the same as that of Stage 1 . The maximum temperature difference found in this stage was around $4.58^{\circ} \mathrm{C}$ 


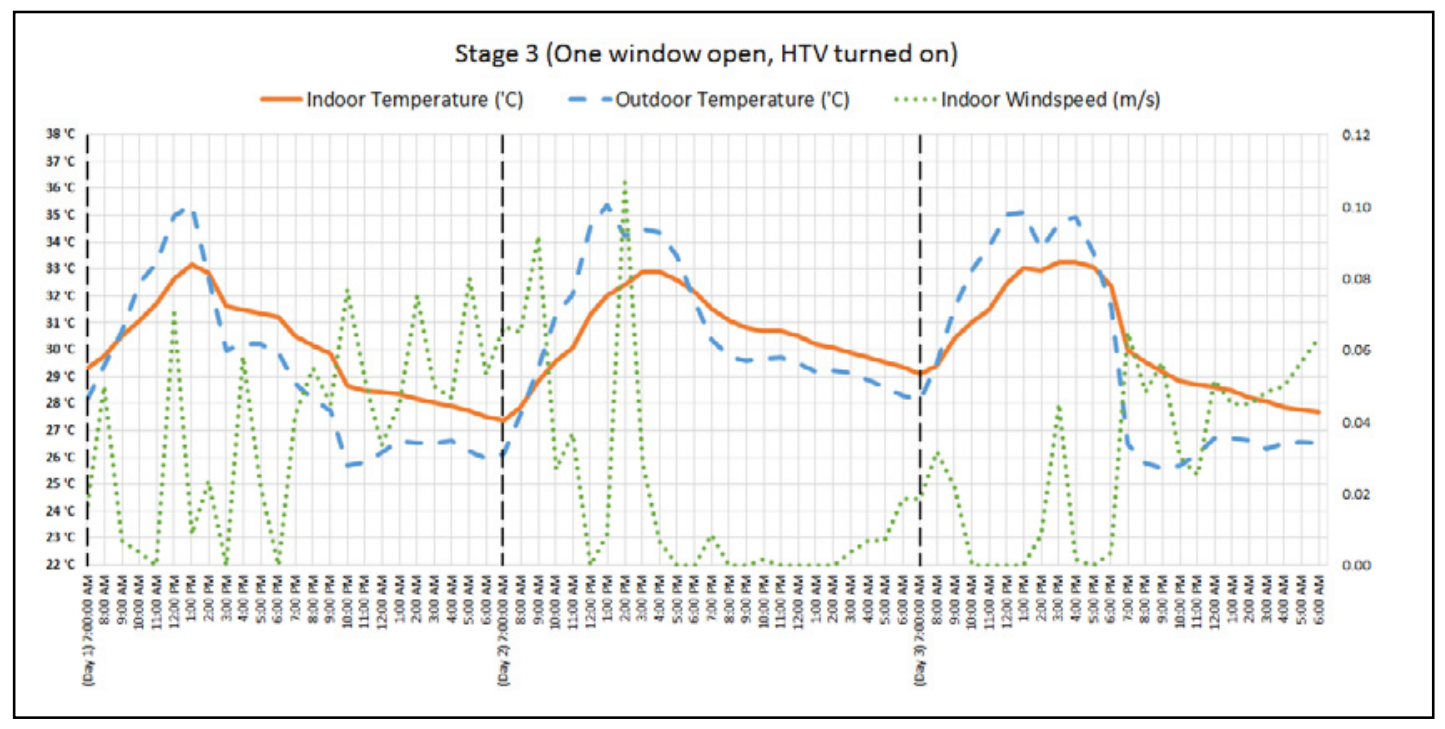

Figure 4 (c): Indoor air temperature at Stage 3

c. Stage 3: The thermal behavioural pattern of the indoor and outdoor air is typical as in the other graphs above but the behaviour of the air movement was erratic. This is a typical characteristic of a tropical wind, being erratic, unpredictable and multi-directional. Nevertheless there was active air movement throughout the three days although the required air velocity for thermal comfort was not achieved. This is compared with Stage 2 . The maximum temperature difference found here was $3.38^{\circ} \mathrm{C}$.

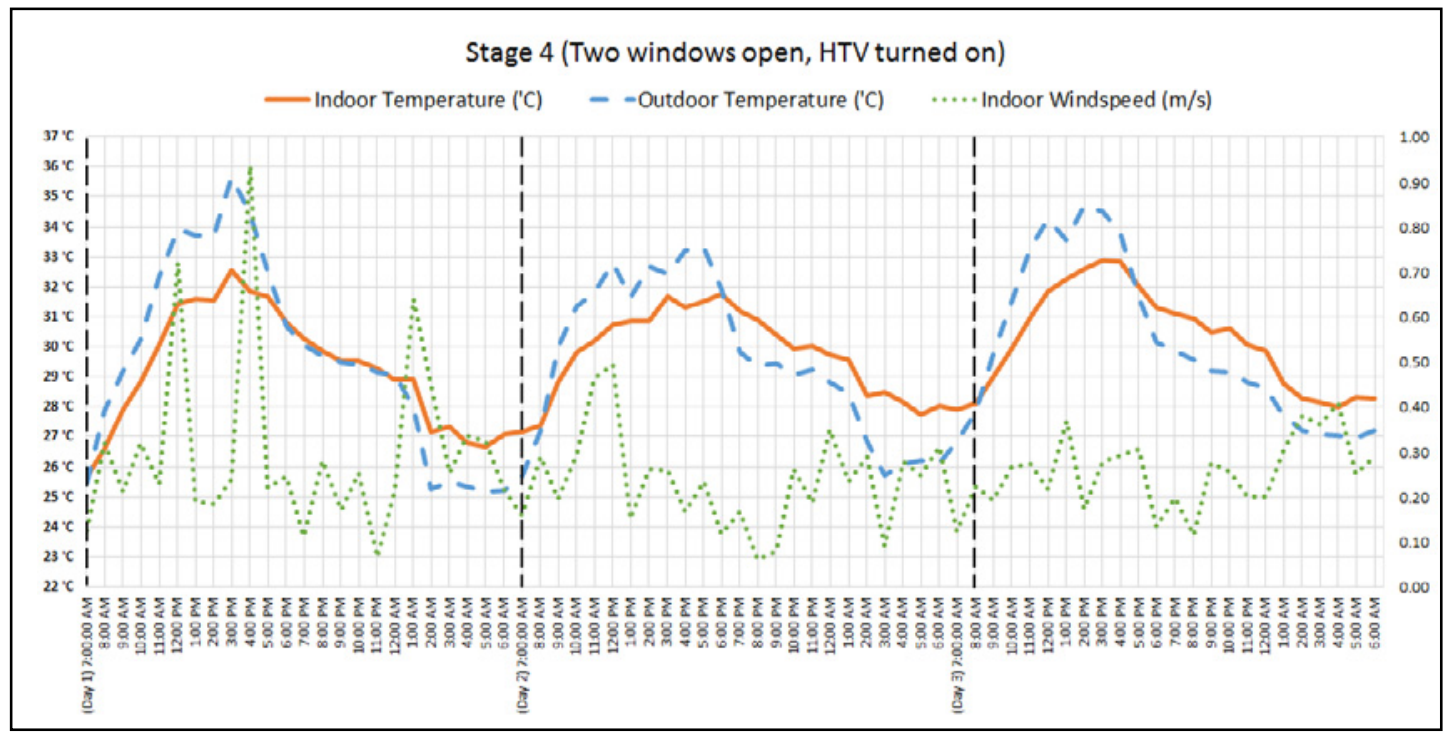

Figure 4 (d): Indoor air temperature at Stage 4

d. Stage 4: This stage seemed to be the best for relying on natural cross ventilation. This can be seen from the active air movement; most recorded above $0.1 \mathrm{~m} / \mathrm{s}$, averaging about 0.2 to $0.4 \mathrm{~m} / \mathrm{s}$. However, in reality to actually achieve thermal comfort, it is reported that an air movement of at least $1.0 \mathrm{~m} / \mathrm{s}$ is required. The indoor air temperature remains below the outdoor air temperature, starting between 6.00 to 7.00am and crossed paths at between 5.30 
to $6.00 \mathrm{pm}$, an average of about 11 hours after which an interesting pattern developed unlike that of the two closed condition cases as mentioned above. After the indoor and outdoor temperatures crossed path, both ran parallel with a very small difference although the indoor temperature was higher than the outdoor air temperature. The maximum temperature difference found for this stage was $3.11{ }^{\circ} \mathrm{C}$

To determine the potential of the hybrid turbine ventilator, this paper conducted a simplified comparison of air temperatures for the hottest days under clear sky conditions from each strategy as mentioned earlier. However, a comparison of the conditions of the varied strategies during the various days indicated that each day had slightly different climatic situations. As a result, a simplified comparison using the relativeness index $(\Delta T)$ as an indicator was conducted to formulate general assumptions. Figure 5 shows the comparison of $(\Delta \mathrm{T})$ indoor-outdoor temperature differences among the hottest days for all of the strategies. As shown in the graph, strategy 2 clearly decreased the indoor air temperature relative to the outdoor air temperature, particularly on its hottest day of data collection when the level of solar radiation was very high, achieving a difference of more than $4{ }^{\circ} \mathrm{C}$ around 02:00pm.

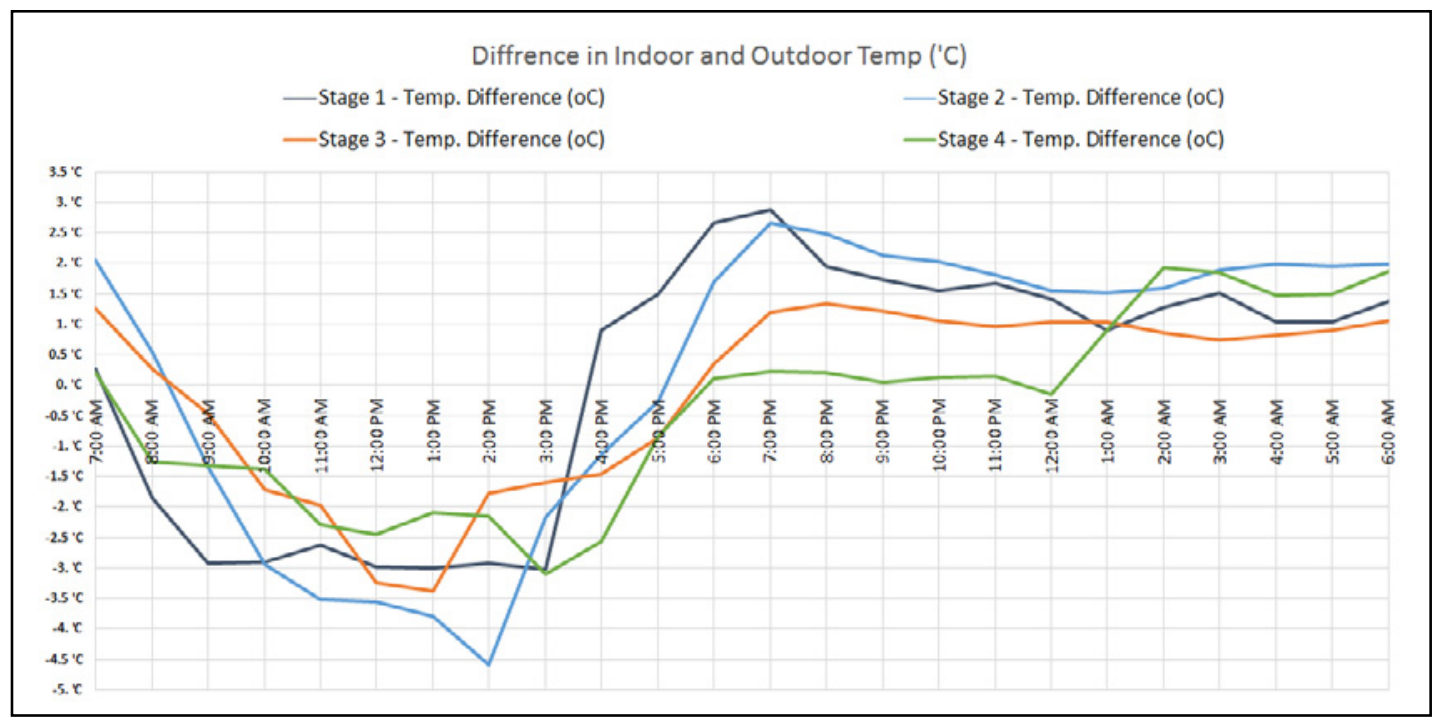

Fig. 5: Temperature difference for the four stages of experiment (days with maximum temperature difference)

In addition, the figure also indicated that stages 3 and 4 showed an interesting reduction which hits around $3.38{ }^{\circ} \mathrm{C}$ for stage 3 and near $3.11^{\circ} \mathrm{C}$ for stage 4 . In fact, stage 4 presented more fluctuated and unstable readings because of the effect of wind movement from the two windows. However, stage 3 showed more steady performance due to the mechanism of air circulation from inlet to outlet. In general, the pattern of readings showed a maximum reduction around $12-3 \mathrm{pm}$ when the impact of solar radiation was high. As a result, this indication shows that the mechanism of the HTV, even when it is applied with different strategies, relies mostly on the level of solar radiation to improve the operation of the HTV.

\subsection{Relative Humidity and indoor wind velocity.}

Figure 6 compares the relative humidity for the four stages and confirms the behaviour of the indoor climate. It can be noticed that the stage with two windows open recorded the highest humidity during the night as the cross ventilation decreased the indoor temperature the most, but at the same time the air brought in a lot of moisture into the room. Even with one opening the relative humidity is higher 
than the two closed condition. At night, the average was about $75 \%$ to $85 \%$ and this is considered a discomfort zone for tropical living, when there is no air movement indoors.

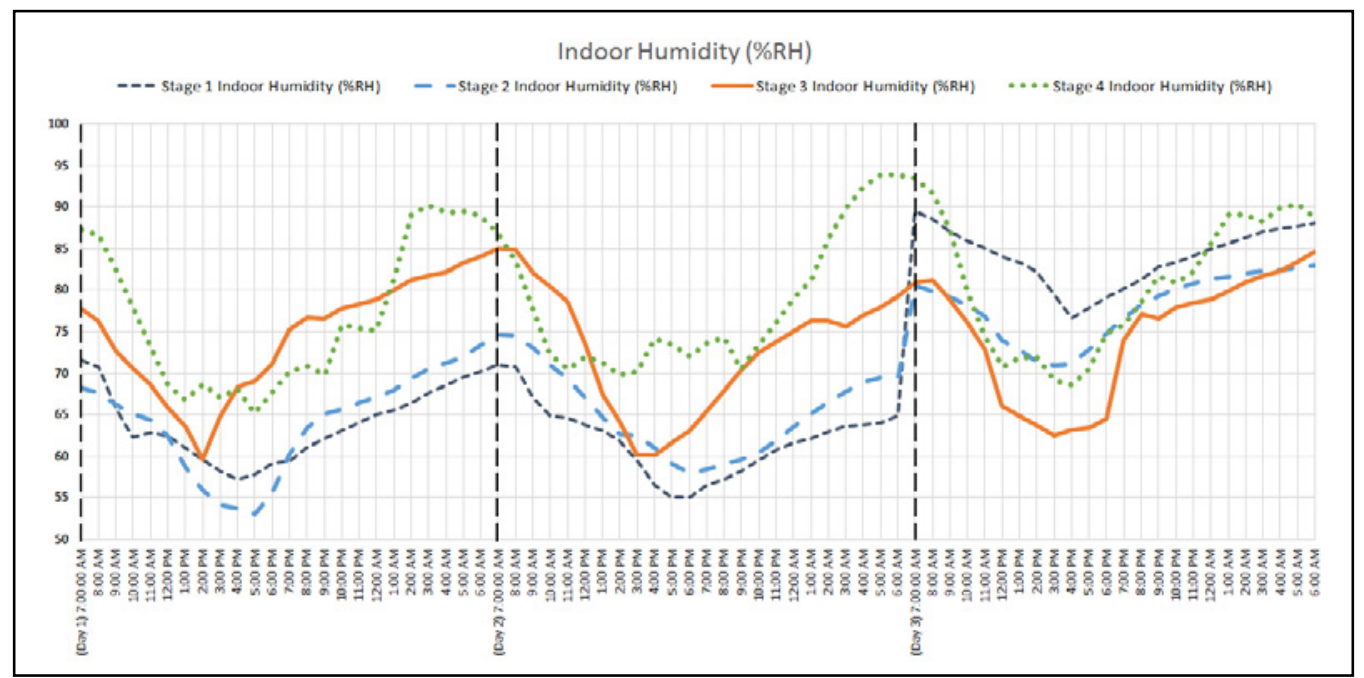

Fig. 6: The relative humidity pattern for four stages.

During the hours of maximum radiation and outdoor temperature, the humidity percentages were the least for all four stages. Besides that, the room at the stage of least ventilation had the least indoor humidity. That is why stage one had a lower percentage of humidity, where everything was closed, than the strategies where there were some sort of ventilation.

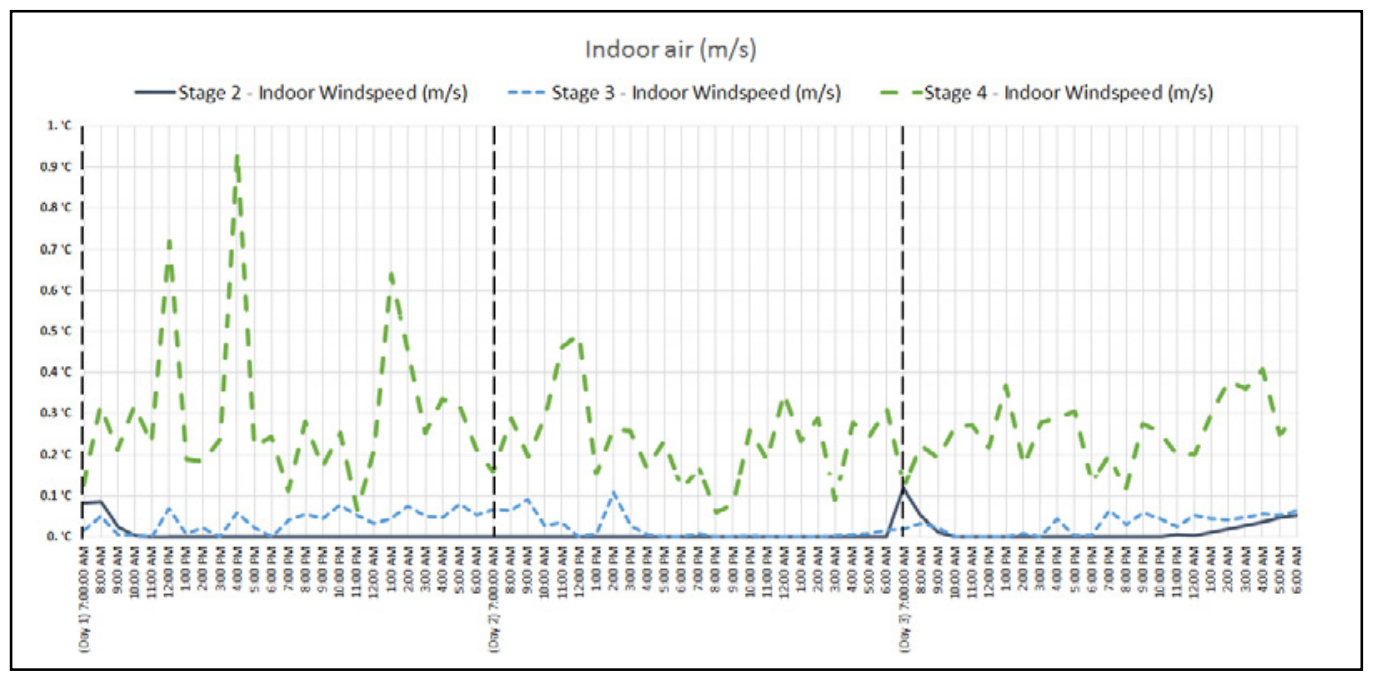

Fig. 7: The real scale model for the empirical study

The indoor air velocity in the vented stages (Fig. 7) was the highest for the stage with cross ventilation, but the velocity in the third stage where only one window was open, showed a rather lower velocity compared to the previous one. However, the indoor air velocity was only significant during the beginning of day time, which was around $7 \mathrm{am}$. 


\section{Conclusions}

Stage 1 was done to see the baseline condition and only used as a reference point for the worstcase condition, and cannot be used as indoor human comfort design. Stage 2 was just the next development to see how the indoor climate behaves when the HTV was on but openings still remained closed. Stage 4 can be said to be the best to achieve thermal comfort with both windows opened, but because the inlet and outlet of openings are only 4 meters away from each other, there is doubts as to whether the HTV has any real impact on the air change. This research was to find out how effective the HTV is in aiding temperature reduction and because Stage 4 was doubtful, Stage 3 was done to determine whether one opening would show the performance of the HTV. This means that to make a meaningful comparison only Stage 2 and Stage 3 were selected. It was found that the indoor environmental condition is not good with one window without the HTV, but improved remarkably when the HTV was introduced. So when a design situation allows for only one opening, installing an HTV would be the solution for using renewable energy.

\section{References}

1. Bastide, A., Lauret, P., Garde, F., \& Boyer, H. (2006). Building energy efficiency and thermal comfort in tropical climates: Presentation of a numerical approach for predicting the percentage of well-ventilated living spaces in buildings using natural ventilation. Energy and buildings, 38(9), 1093-1103.

2. Kuo, I. S., \& Lai, C. M. (2005). Assessment of the potential of roof turbine ventilators for bathroom ventilation. Building Services Engineering Research and Technology, 26(2), 173-179.

3. Khan, N., Su, Y., Riffat, S. B., \& Biggs, C. (2008). Performance testing and comparison of turbine ventilators. Renewable Energy, 33(11), 2441-2447.

4. Lai, C. M. (2006). Prototype development of the rooftop turbine ventilator powered by hybrid wind and photovoltaic energy. Energy and Buildings, 38(3), 174-180.

5. Ismail, M., \& Rahman, A. M. (2010). Comparison of Different Hybrid Turbine Ventilator (HTV) Application Strategies to Improve the Indoor Thermal Comfort. International Journal of Environmental Research, 4(2).

6. Al-Obaidi, K. M., Ismail, M., \& Rahman, A. M. A. (2014). A comparative study between unvented and vented attics powered by the hybrid turbine ventilator in Malaysian houses. International Journal of Sustainable Energy, (ahead-of-print), 1-13. 